\title{
Clinical Implications of Nasal Septal Deformities
}

\author{
Ranko Mladina ${ }^{1}$, Neven Skitarelić ${ }^{2}$, Gorazd Poje ${ }^{1}$, Marin Šubarić ${ }^{3}$ \\ ${ }^{1}$ Department of Otolaryngology Head and Neck Surgery, Clinical Hospital Center Zagreb, University of Zagreb Faculty of Medicine, Zagreb, Croatia \\ ${ }^{2}$ Department of Otolaryngology Head and Neck Surgery, General Hospital Zadar, Medical High School, University of Zadar, Zadar, Croatia \\ ${ }^{3}$ Department of Otolaryngology Head and Neck Surgery, Clinical Hospital Dubrava, Zagreb, Croatia
}

The first attempts to systematize septal distortions have been given by Cottle who defined four groups of septal deformities: subluxation, large spurs, caudal deflection and tension septum. Fortunately, the variations of the septal deformities show a certain order, thus enabling more precise classification. Mladina was the first to make user-friendly classification of septal deformities in six basic types. He also described the seventh type, named "Passali deformity", which presents individually, but is always a well-defined combination between some of the previous six types. Mladina types of septal deformities (SD) are divided in two main groups: so called "vertical" deformities (types 1, 2, 3 and 4), and "horizontal" ones (types 5 and 6). This classification was immediately well accepted by rhinologists worldwide and started to be cited from the very beginning. Since then it has been continuously cited increasingly more often, thus making Mladina classification a gold standard whenever clinical researches on nasal septum are concerned. More than forty clinical studies based on this classification have been performed to date. It is extremely important to make a strict distinction between the types of SD since all of them play some specific role in the nasal and general physiology in man.

Keywords: Classification, nasal septum, nose deformities
First of all, one should determine a difference between the term septal deviation and septal deformity, since "deviation" generally means a slight declination from the medio-sagittal plane, whereas deformity means the change of shape or change of form. The basic form of the septum should mostly be a straight plane that divides the nose into two cavities, but in reality it is not like that. Many authors have tried to delve deeper into the problem of variations in septal shape. Because of that, there were almost no data published on the matter of the relationship between particular septal deformities (SD) and the related health problems, be it local or general, until the early 1990s. The first attempts to systematize septal distortions were given as early as 1958 by Cottle (1) who defined four groups of "septal deviations": subluxation, large spurs, caudal deflection and tension septum. Fortunately, the variations of the septal shapes (deformities) show a certain order, thus enabling more precise classification. In 1987, Mladina was the first to make user-friendly classification of (SD) in six basic types (2). He also described a seventh type, named Passali deformity, which presents individually, but is always a well-defined combination of some of the previous six types. Mladina types of SD are divided into two main groups: socalled vertical deformities (types 1, 2, 3 and 4), and horizontal ones (types 5 and 6). Vertical deformities have the longer axis in a vertical plane, i.e. they concern the unilateral $\operatorname{crook}(\mathrm{s})$ that can be imagined as a result of the force acting against the nasal septum in an antero-posterior direction. The horizontal deformities, however, have a longer axis in the horizontal plane, i.e. they are crooked as if the force against the septum has been acting from superior to inferior. This classification was immediately well accepted by rhinologists worldwide and was cited from the very beginning. The number of citations 


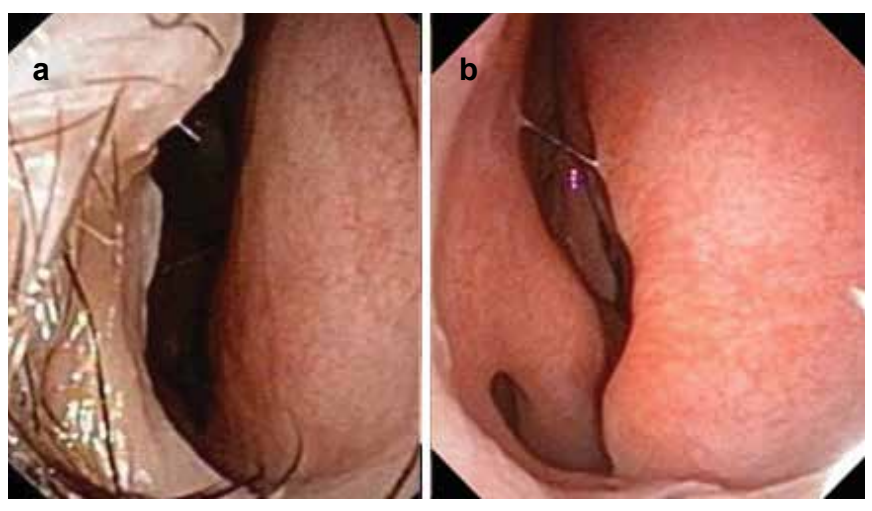

FIG. 1. a, b. Right-sided septal deformity type 1 (a). Right-sided septal deformity type 1 . Inferior turbinate can be followed almost the entire way to the choana. The anterior half of the middle turbinate can also be easily seen (b).

has been growing since then, and this has been the standard method at least 40 clinical researches in various countries all over the world (3-42).

Twelve years after Mladina published his classification and after it had been used for many clinical researches, in 1999, Guyuron published his suggestions, promoting six types which, at first sight, seemed to be more user friendly than Mladina's (43). Guyuron suggested the following types: tilt, antero-posterior C, antero-posterior S, cephalo-caudal S, cephalo-caudal $\mathrm{C}$, and wide spurs. This classification, as for that described by Mladina, includes six types of SD. Moreover, his antero-posterior C corresponds to Mladina type 3, the antero-posterior $\mathrm{S}$ looks exactly like Mladina's type 4, the cephalo-caudal $\mathrm{C}$ is extremely rare and exists only as an exception after the really serious trauma to the nose (superiorinferior direction of force), and, finally, the cephalo-caudal $\mathrm{S}$ is extremely similar to Mladina's well-known type 6. Finally, so-called "wide spurs" are the same as Mladina's type 5. Therefore, overall, both classifications describe almost the same deformities but in "different languages".

Four years later, in 2003, Buyukertan classified SD by separating the nasal septum into 10 segments with an intention to better localize the deformity (44).

After that, in 2007, the Baumanns published a new classification of septal "deviations" (45). According to their schematic drawings, not real endo-photographs, types 1 and 2 appear to be the same as Mladina's type 5, their type 3 corresponds to Mladina's type 6 , types 4 and 5 are very similar to type 7 , i.e. a combination of type 5 and type 2 in their type 4 , and type 5 and type 3 in their type 5, whereas their type 6 very closely resembles Mladina's type 3. However, the Baumanns' classification does not include "S-shaped" or "reverse S-shaped" septums, i.e. Mladina's type 4 or Guyuron's "anterior-posterior S".

Some studies on the incidence of SD in man, based on the Mladina classification and simple anterior rhinoscopy without the decongestion and endoscopy of the nose, showed the incidence of septal deformities to increase slowly from childhood to adulthood, finally becoming very high, reaching close to $90 \%$ of the population in the world (29-31).

Once it became obvious that SD in man are well defined and differ between themselves, it became very interesting to see how a particular type of septal deformity can influence the owner's nose. We have been using the Mladina classification since 1987 and have realized the close relationship between some of them and the related sino-nasal pathology.

\section{CLINICAL IMPLICATIONS Of SEPTAL DEFORMITIES}

Type 1 means a mild unilateral vertical ridge in a valve area which slightly interferes with the function of the nasal valve; thus, in most cases, this has mild clinical importance (Figure 1a, b).

Clinically, some people, for reasons which are unclear, tolerate this type better than others. The exception could appear when this type is connected to subluxation or even luxation of the columellar septal edge. The subluxation or luxation could bother patients both aesthetically and functionally sense, while the septal deformity type 1 is, in most cases, irrelevant in terms of the patient's subjective valuation of nasal breathing quality.

Exceptionally, it can act as a predilection factor for impaired nasal breathing in patients with unusually high columella and thin, flagging alar cartilages. In these cases, the entrance to the nose is already narrower than usual since a high columella enables a certain degree of nasal alae stretching. In cases where they are thin and lax, they will collapse during deep nasal breaths. The result will be the nestling of both alae to the anterior septum, which will be much stronger on the side of the deformity (Figure 2a, b).

Type 2 means a unilateral vertical ridge, which is much more emphasized in this case, i.e. it stays in close contact with the anterior nasal valve and thus, from the physical point of view, remarkably narrows or even totally blocks the air passage on the related nasal side.

From the clinical point of view, the shape of this deformity produces a typical situation: the buds of the nasociliary and palatinal nerves (belonging to $\mathrm{V}_{1}$ and $\mathrm{V}_{2}$ branches of the trigeminal nerve), which have a dense network in the nasal cavity, do not have appropriate contact with the airstream of the inspired air. In fact, they cannot be adequately agitated by the airstream produced while passing through the nose. Because of that, the beginning of the afferent arm of the socalled naso-pulmonary reflex that connects the nose and the lung is blocked and the nuclea of the trigeminal nerve in 
the medulla oblongata cannot be reached and agitated. Furthermore, the closest "neighbors" to the trigeminal nuclea in the medulla oblongata are nuclea of the cervical plexus. In addition, the phrenic nerve is located within the cervical plexus. The phrenic nerve, furthermore, is responsible for the innervation of diaphragm muscles (efferent arm of the naso-pulmonary reflex). Because the phrenic nerve cannot be adequately agitated in these circumstances, no consequent contraction of the diaphragm muscles can be expected on the related thoracic side. Furthermore, a weak contraction of the diaphragm also results in more superficial pulmonary breathing on this side. In addition, septal deformity itself disables a direct contact between the airstream and nasal fontanel receptors, thus impeding normal regulation of the

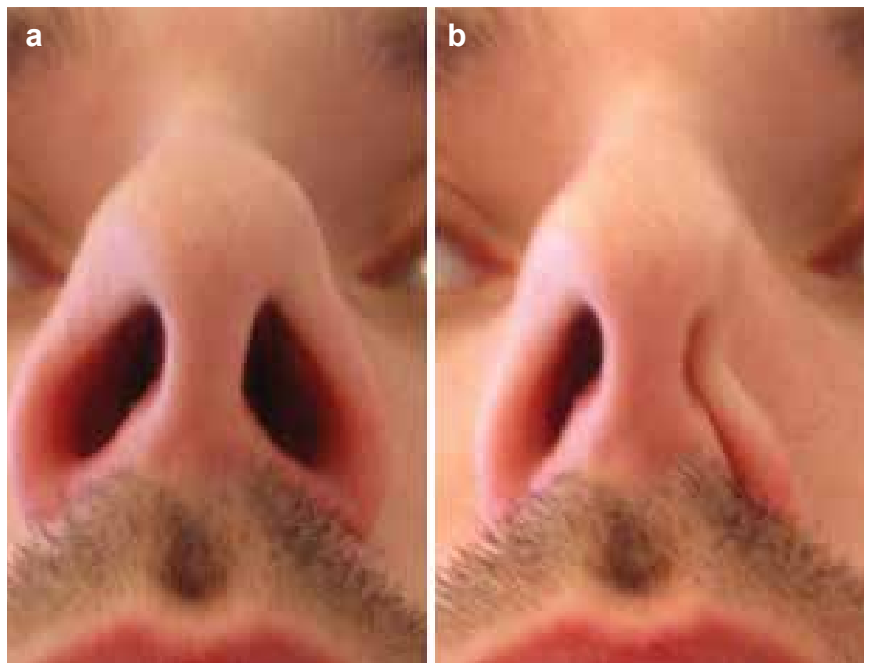

FIG. 2. a, b. Typical shape of the nostrils during normal nasal breathing (a). During the forced inspiration through the nose, the left, flagging ala adheres strongly to the septum, thus blocking any further nasal breathing through the left nose (b). tracheobronchal vagal tone. The naso-pulmonary reflex is distorted or totally blocked (46-48). Therefore, the most important clinical feature connected to the type 2 septal deformity is impaired nasal and pulmonary breathing.

One should not forget the usual endoscopic finding of the most posterior parts of the nasal cavity in type 2: a strawberrylike hypertrophy of the mucosa of the inferior turbinate tail (Figure 3a-c).

Even more, there are data in the literature that suggest the strong influence of type 2 , combined with the consequently hypertrophic mucosa of the tail of the inferior turbinate, to the middle ear pressure (23).

Type 3 means unilateral vertical deformity, i.e. unilateral convexity next to the anterior edge of the head of the middle turbinate (Figure 4). The nasal cavity is very narrow on this side and very wide on the opposite one.

From a clinical point of view, it must be stressed that type 3 is the most frequent septal deformity in the general population and very frequently found in all cases of chronic rhinosinusitis (CRS). The incidence of type 3 in CRS patients was $21.63 \%$ (41). In addition, the allotment of the type 3 within type 7 among adults suffering from CRS was found to be almost $90 \%$. Since type 7 was found to be present in $29.92 \%$ of CRS patients, this suggests that type 3 is the most frequent SD in CRS patients.

Here, one should not forget the fact that pathohistological analysis of the mucosa taken from the most convex and most concave part of the nasal septum in type $3 \mathrm{SD}$ has shown a multilayer squamous cell metaplasia $(6,12)$ (Figure 5). The same has been shown in the mucosa covering the head of both middle turbinates. In such conditions, with no trace of cylindrical respiratory epithelium, one cannot expect to have a normal mucociliary clearance system, which is important and typical for the respiratory system. The metaplastic multilayer

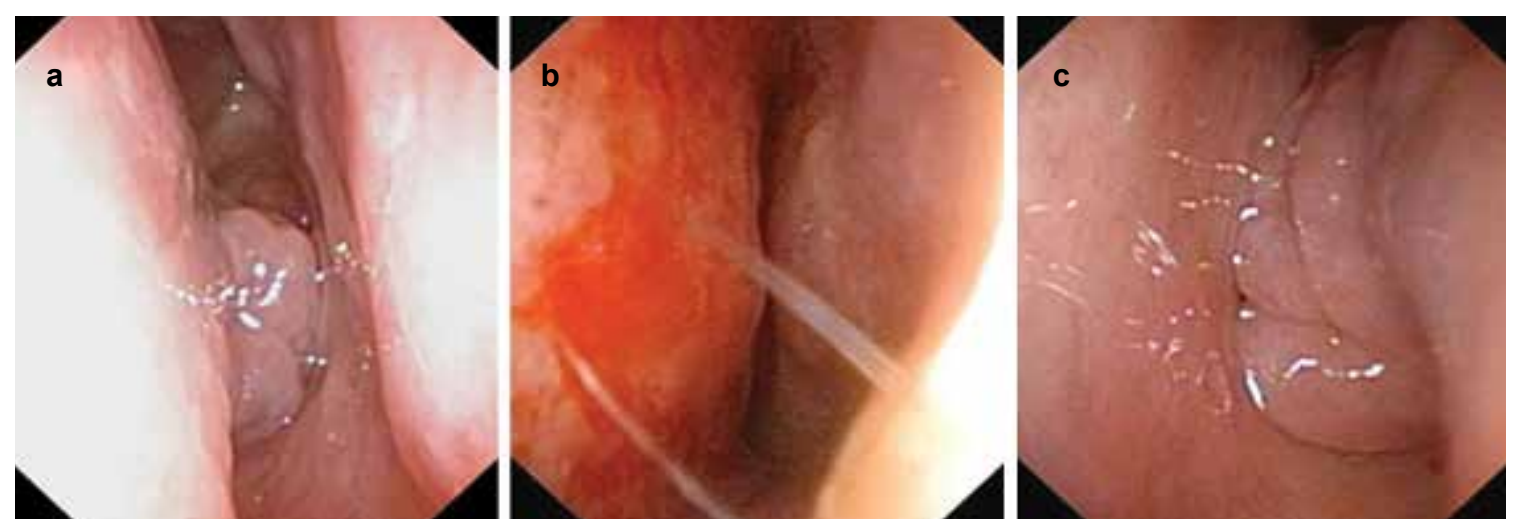

FIG. 3. a-c. Right nasal cavity. Choana is blocked by hypertrophic mucosa of the inferior turbinate tail (a). Left-sided type 2 septal deformity (b). The same situation is seen with the mucosa of the left inferior turbinate tail. Please note that the endo-photographs were taken after comprehensive decongestion and superficial anesthesia with xillocaine spray. In the native status, the "cork" in the choanae is usually bigger and blocks the choana much more tightly (c). 

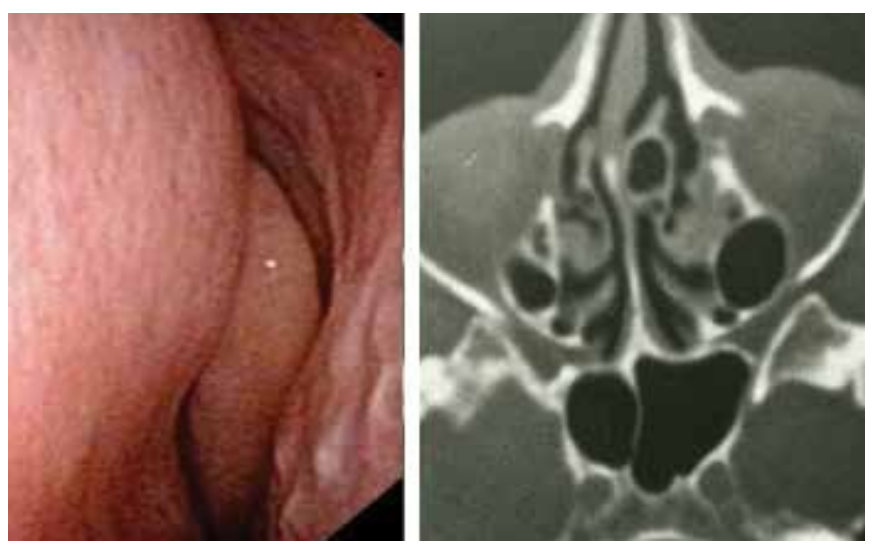

FIG. 4. Left-sided type 3 deformity. Although nasal decongestant and local superficial anesthesia have been applied, the deformity covers the view to the great part of the middle turbinate and remains in close contact with it.

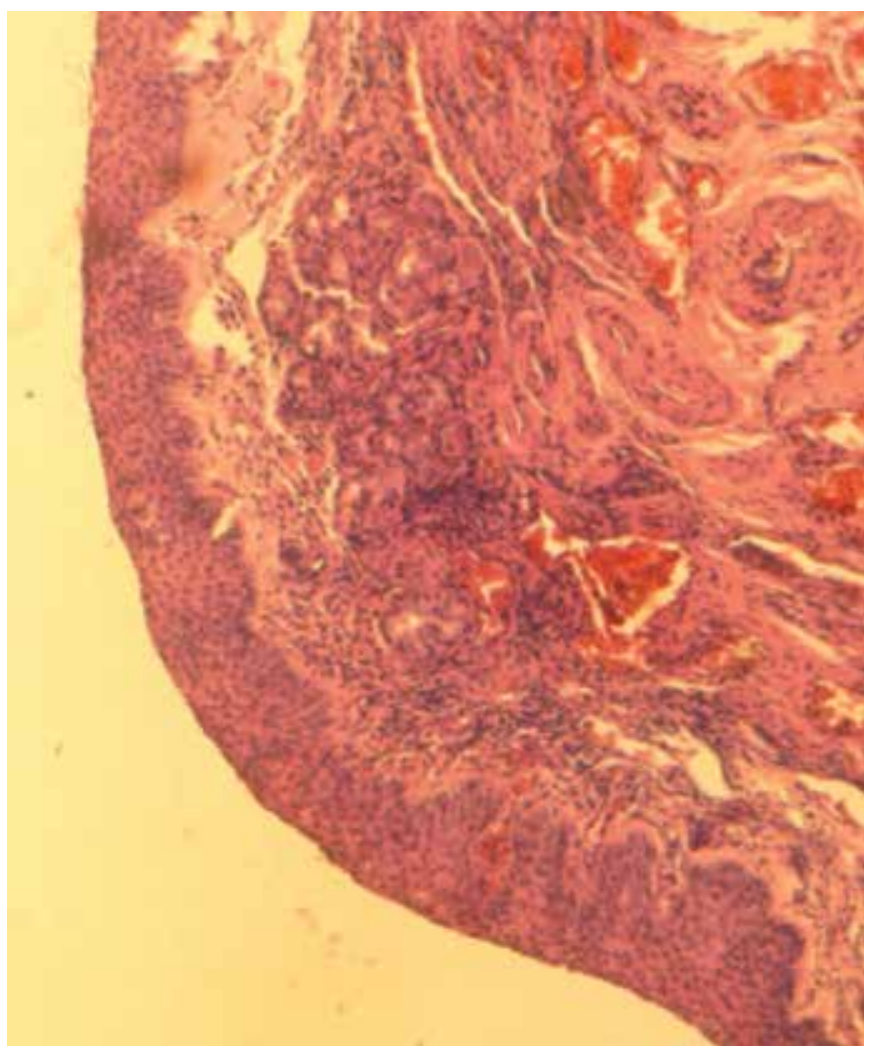

FIG. 5. The right-sided type $3 \mathrm{SD}$. Histological picture of the piece of septal mucosa taken from the narrowest part of the nasal cavity, just opposite the head of the middle turbinate. The epithelium shows typical appearance of the squamous cell metaplasia.

squamous cell epithelium allows only the stagnation and final block of the mucociliary transport system, thus widely opening the door for bacterial and viral invasion.

In most of the cases with a bent (scoliotic) external nose ("C" or "reverse-C" shape of the external nose), the background is type 3 septal deformity. Therefore, an adequate cor-
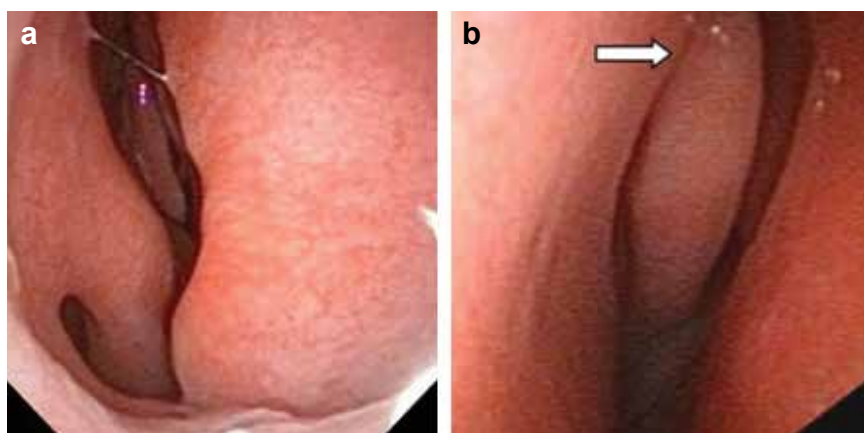

FIG. 6. a, b. "Z-shaped" type 4 SD. Right-sided type 2, staying very close to the head of the inferior turbinate despite the abundant decongestion and local superficial anesthesia (a). Left nasal cavity shows much deeper vertical deformity (white arrow), just next to the head of the middle turbinate (type 3 ), despite the previous decongestion (b).

rection of the scoliotic nasal pyramid always requires appropriate septal surgery.

Type 4 is a bilateral vertical deformity (Figure 6), consisting of previously mentioned types, i.e. type 2 on one side, and type 3 on the other (so called "S- shaped" septum, or "reverse S-shaped" septum). Clinically, it summarizes all clinical implications of both types.

Type 5 is a unilateral deformity, which is known in the literature as a "septal spur". It causes a unilateral horizontal deformity, discretely ascending from anterior to posterior, appearing as a crest which juts out more laterally than deeper in the nose, resulting in most cases in the impaction of its tip to the region of the sphenopalatine foramen (Figure 7a, b).

Clinically, it always means unilaterally impaired nasal breathing. The opposite side of the septum is almost flat. Sometimes, this deformity can provoke ipsilateral intermittent attacks of the headache, so called hemicranial pains (Sluder's headache), since the tip of the deformity is in close contact with the sphenopalatine cable containing the sphenopalatine artery, vein and a nerve in this case.

More theoretically, this type could also influence the development of chronic otitis media since it mechanically disturbs the normal flow-direction of mucous drainage from the ostiomeatal complex to the nasopharynx, just directing it more superiorly, i.e. towards the Eustachian tube orifice, because mucous flow has to skip the dam, i.e. the tip of this deformity.

This deformity is also one of the most frequent in the general population. Its incidence is low in childhood and starts to grow by adolescence, achieving full frequency in adults when it finally reaches around $28 \%(3,29)$.

Fortunately, despite the fact that, in most cases of type 5, the native anterior rhinoscopy simply enables this deformity to remain undiscovered behind more anterior parts of the nasal cavity mucosa, endoscopy of the nose is not mandatory: it can 


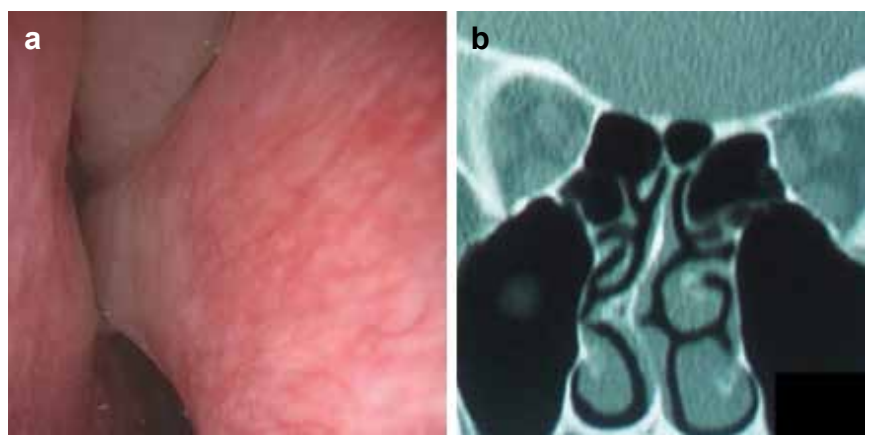

FIG. 7. a, b. Right-sided type 5. Right-sided, typically deep and in most cases hidden and (without the decongestion) invisible horizontal basal crest, getting in a very close contact to the lateral nasal wall as getting deeper in the nose (a). Coronal MSCT scan clearly shows type 5. How deep the position of the deformity peak is can be easily assessed by looking at the anatomy of the orbit: only the orbital apex is presented in this scan, i.e. only the shadows of extra-ocular muscles, optic nerve is hardly visible, while the eyeball remained more anterior (b).
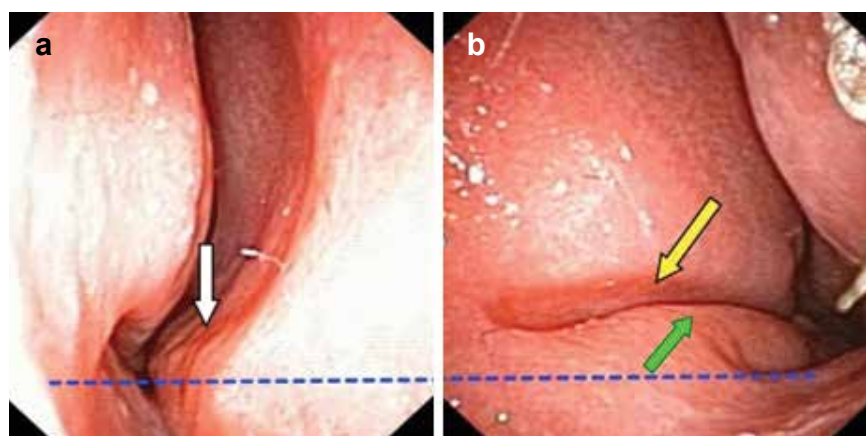

FIG. 8. a, b. An anterior, basal crest can be seen (white arrow). In most cases, it touches the mucosa of the inferior turbinate. This photograph was taken after the decongestion and superficial local anesthesia; thus, much closer contact between the crest and inferior turbinate can be presumed and imagined (a). The typical septal groove is located on the opposite septal side (yellow arrow); intermaxillary bone wing contours are clearly presented (green arrow) (b). Blue dotted line shows that the left nasal floor stays at the higher level than the right one: this is very typical for type 6 .

also be seen and recognized on the coronal MSCT scans of the paranasal sinuses (Figure 7b).

This deformity seems to be inherited, since it is usually found in close relatives in a particular family (patient's closest relatives). The side of the deformity and its intensity are not usually the same, but there is always a typical appearance of this type.

Type 6 is also a so-called horizontal deformity, consisting of two separate components: an anteriorly positioned basal septal crest on one side and more or less massive wing of the inter-maxillary bone on the opposite side. Between the intermaxillary bone wing and the septum there is a horizontal groove. The groove is a strict characteristic which determines type 6 (Figure 8a,b). It can be shallow and very deep; this does not matter at all. Its existence is crucial even when extremely shallow.
Clinically, type 6 is found in more than $96 \%$ of all children suffering from cleft lip/palate, and in more than $76 \%$ of their parents (39). Additionally, in adult subjects carrying type 6 SD without a manifest cleft, one must palpate the hard palate (submucosal cleft?), take a precise look at the uvula (bifid or not?), and perform an obligatory analysis of the subject's hearing abilities because submucosally hidden weakness of the palate could also mean a weakness of levator veli palatini and tensor veli palatini muscles. The weakness of these two muscles directly influences normal function of the Eustachian tube orifice, thus also influencing ventilation and drainage of the middle ear, which directly leads to the possible ipsilateral conductive hearing impairment.

Type 6 can be found in the vast majority of patients suffering from REKAS (Recurrent Epistaxis from Kiesselbach's Area Syndrome) (49,50). Finally, there is another similarity: as in type 5 , this type can also be easily recognized on coronal MSCT scans (Figure 9).

This deformity, like type 5, also seems to be inherited (38), since it can be found in all members of the family (patient's closest relatives). Like in type 5, the side and intensity are not necessarily the same as in the index patient, but a typical appearance is always present. The deep anterior groove defines the side of the deformity, i.e. if the patient carries type 6 with the groove on his left side, the deformity should be recorded as "Type $6 \mathrm{~L}$ ". The anterior basal crest therefore is located on the opposite side.

Type 7 ("crumpled septum") is very variable and presents a combination of previously mentioned types with all of their clinical implications (Figure 10). In fact, it always involves a combination of one of two horizontal deformities (type 5 and/ or type 6) with one of those belonging to so-called vertical deformities (types 1,2,3 or 4).

\section{DISCUSSION}

\section{General considerations}

Septal deformities appear in six well-defined types, and also as a combination of some of them in many cases, which are called type 7 "crumpled septum".

It is extremely important to make a strict distinction between the types of SD since all of them play a specific role in nasal and general physiology in man.

It is absolutely irrelevant whether one call some type of septal deformities by number or an abbreviated name, or distinguish them according to the shorter or longer verbal descriptions. However, to us it appears to be much easier to simply use numbers.

For a single septal spur (or crest), our classification has a simple sign: type 5. However, to assign some "crumpled sep- 


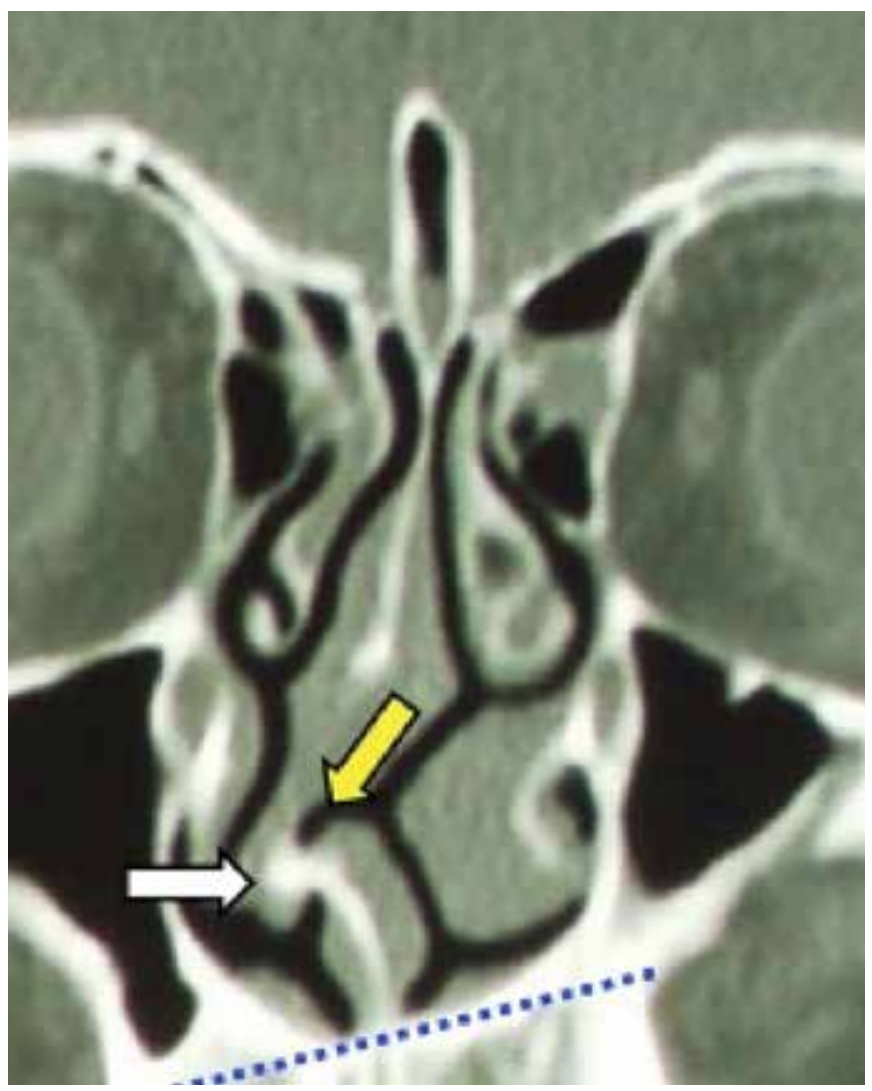

FIG. 9. Coronal MSCT-scan of the paranasal sinuses. Septal deformity type 6 is clearly recognizable with a typical groove (yellow arrow) and basal crest (white arrow). Dotted blue line shows the asymmetry of the nasal floor, which is always found in this type of septal deformities.

ta" is not that easy. If verbally described, it will take at least one or, more probably, two lines of typewriting. On the contrary, to say, for example, "Type 7 (type 3 right+ type 5 left)" means that there is a "crumpled septum", i.e. for a combination between right-sided type 3 and left-sided type 5 . This will not be possible when using Guyuron's classification since it does not offer type 7 at all.

As all of us are dealing with the problem of deformed nasal septa, deprived from any vanity, it is necessary to speak the same language regarding the types of SD; this will enable the general knowledge on this matter to certainly blossom. It is difficult to compare individual results until we speak different languages and thus do not understand each other.

In addition, the term "septal fractures" has been firmly accepted and used among rhinologists for years and decades despite the fact that it is purely used for dogmatic apprehension. Namely, it should be known that even in cases of obvious anterior vertical crooks of the nasal septum (types 1 and 2), no obvious "fracture" of the cartilage or any tissue gap was found, be it during the septal surgery or during the histological analysis. Regarding histology, the only issue that can normally
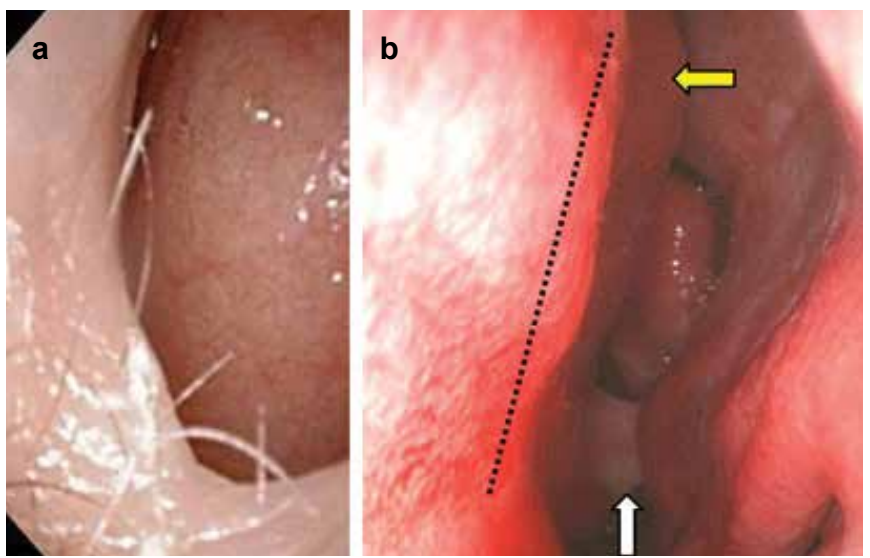

FIG. 10. a, b. Clinical appearance of type 7 (Passali deformity or "crumpled septum"). The right nasal cavity is almost completely blocked by the septal deformity (a). Left cavity, after decongestion and application of the superficial local anesthetic, showed type 3 (yellow arrow) and an emphasized type 5 in the deepest areas (white arrow). This deformity cannot be identified by means of a native anterior rhinoscopy in most cases because it remains hidden by the nasal mucosa. The dotted line indicates the internal, caudal margin of the type 2 which fully extends to the right side, obstructing the entrance to the right nose (b).

be found in the region of the crook is local proliferation of the chondrocytes in the "heart" of the deflection (Figure 11a, b). The real disruption of the septal cartilage can be seen exceptionally as a result of serious nasal trauma. In these cases, the tissue discontinuity, i.e. the gap between two or more parts of the cartilage can be identified. Besides, in cases of serious trauma to the nose, the distortions of the pyramid can also be seen (Figure 12).

Type 3, which is also a vertical deformity, but substantially deeper than types 1 and 2, i.e. it is positioned at the borderline between the perpendicular lamina of the ethmoid bone and quadrangular cartilaginous plate (cartilago quadrangularis), never shows any sign of fracture. The conjunction between the bone and cartilage always remains untouched, regardless of how acute the angle between them is.

Besides, insisting on trauma against the nose as an exclusive reason for the onset of type 3 does not seem to be well-founded. Sometimes it is easy to "see through the external nose", i.e. in cases of rhinoscoliosis it is understandable that the septum follows the shape of the external nose, as the canvas would follow the distorted frame (Figure 13). However, in the vast majority of type 3 cases, there are no signs of the distorted external nose at all.

\section{Reliability}

Despite the fact that having a unique, user friendly classification makes reliable multicenter studies on the incidence of nasal SD and their clinical implications possible, all classifications published so far suffer from subjectivity when anterior, vertical 

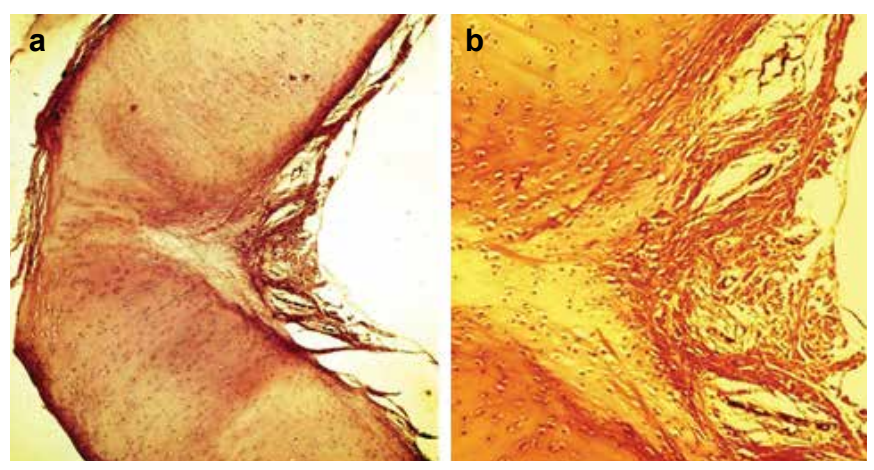

FIG. 11. a, b. Histology of the septal cartilage (horizontal section!) through the right-sided vertical crook (type 2 septal deformity) of an adult patient. Despite an emphasized angulation, there are no signs of discontinuity of the cartilage (a). A close-up view of the angulation shows typical appearance of so called "green stick fracture": no tissue discontinuity (no gap), and the high amount of chondrocytes can be clearly seen invading the damaged place (b).

deformities are concerned: whether some deformity will be assigned as type 1 or type 2 is a matter of the observer's impression since there is no objective parameter which could allow the observer to distinguish between these two types.

However, regardless of that, the most prominent cognitions that we have today regarding the clinical implications of SD are evidence-based. Evidence-based medicine is the future. In terms of that, good classification must have a high degree of reliability. This is particularly important in our case since our classification concerns some important physiologic and pathophysiologic interactive mechanisms between the nose and the organism in general.

For instance, the relationship between type 2 and the quality of pulmonary breathing is well known and has been meticulously described under the section "Type 2".

Type 3 has been found to be the dominant septal deformity in cases of CRS, i.e. the incidence of type 3 in CRS patients was $21.63 \%$ (41). In addition, the allotment of type 3 within type 7 among adult patients suffering from CRS was found to be almost $90 \%$ (41). Since type 7 was found to be present in $29.92 \%$ of CRS patients, this supports the fact that the type 3 is the most frequent SD in CRS patients. Histological changes of the middle turbinate and neighboring septal mucosa have been found on an everyday basis. The consequences of the lack of respiratory mucosa in the crucial nasal regions, responsible for good pulmonary breathing, have been precisely described in the section on Type 3 . Even fontanel receptors have been shown to be blocked in cases of emphasized SD of type 3.

Type 4 summarizes all that which has been stated for types 2 and 3.

Type 5 has been proven to be an absolutely inherited deformity. In the vast majority of unilateral hemicranial headaches

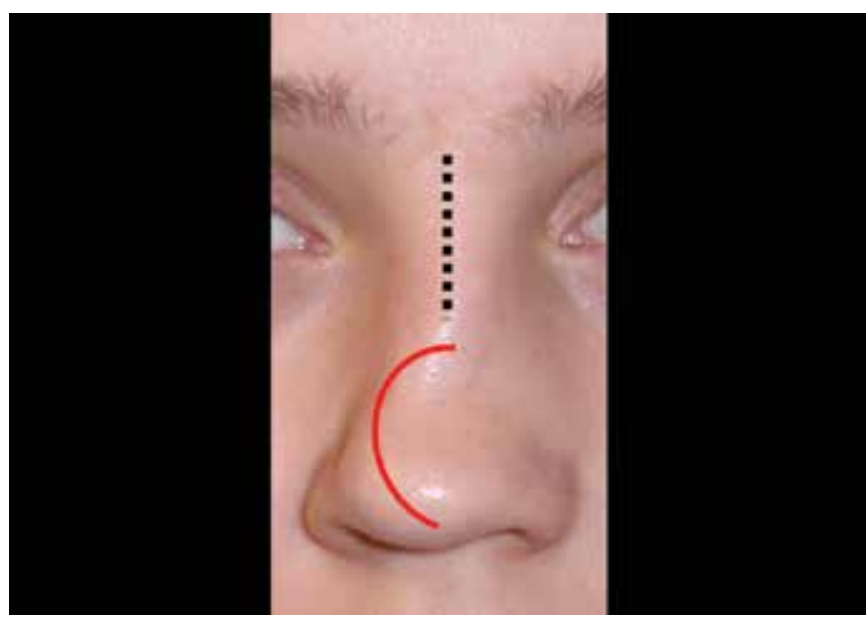

FIG. 12. The appearance of the cartilaginous external nose one year after the latero-lateral trauma against the nose. Please note that the bony frame of the pyramid is still straight (dotted line). The cartilaginous part inclines strongly to the right (red curved line), resulting in the blatant example of type 2 .

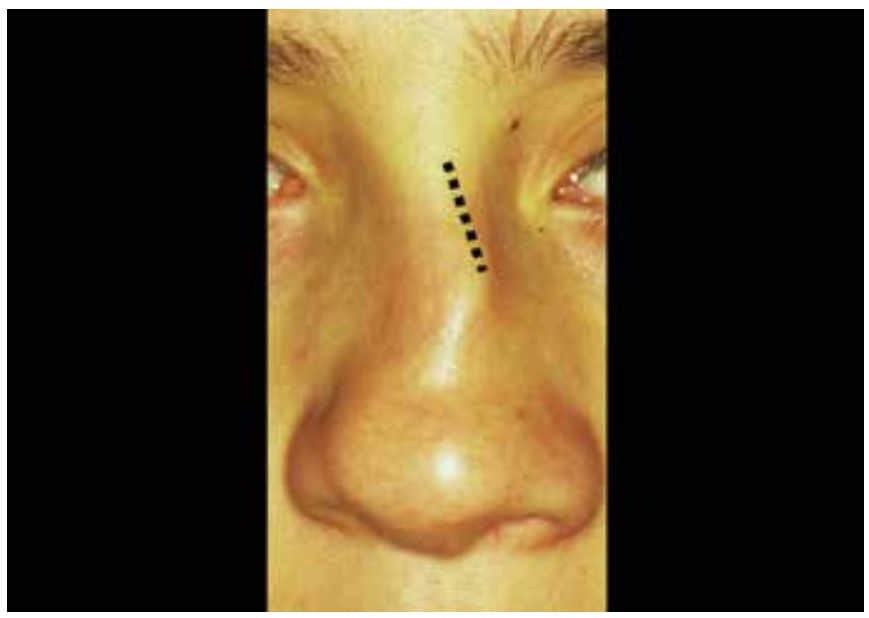

FIG. 13. Rhinoscoliosis ("reverse-C" shaped pyramid). One can presume that such a distorted bony frame brings along left-sided type 3 septal deformity. The bony frame has been distorted (dotted line).

of Sluder's type, type 5 could be found in the deepest parts of the nose. Type 5 has been named septal spur or septal crest for decades, but its heritability has never been mentioned. Owing to this classification, we now know that this deformity can be found in all of the closest relatives in a certain family. This is evidence-based knowledge. Besides, "spurs" have never been explained as a deformity that cannot be found in small children and the fact that it is very rare among children in elementary school, means that this type "comes to the surface" only during puberty and adolescence. Therefore, this fact is evidence-based $(29,43)$.

Finally, now we know that this type is heritable, we know at the same time that it cannot be the consequence of any type of trauma against the nose. 
This knowledge can be useful when the doctor is asked by the court to give an opinion on the consequences of some trauma to the nose. The opinion in such cases will always be the same: this septal deformity has nothing to do with the trauma against the nose.

Type 6 has nothing to do with childhood as well; it is only evident at puberty, step by step, becoming more and more evident in adolescence and reaches its final form only in mature individuals, but again always appears in the closest relatives. Unfortunately, except for the knowledge on this matter based on long-lasting clinical experience, there is no official, published evidence on the absolute heredity of this type at all. On the other hand, the close relationship between type 6 and cleft lip/palate syndrome, REKAS has been clinically proven, thus being an evidence-based matter; this gives some hope that the genetic background for this type of SD will be found in the near future $(39,50)$. If so, perhaps it will be possible to change the constellation of those genes in the individuals carrying type $6 \mathrm{SD}$. This hypothetic removal of the "bad guys" from the organism presumably could dramatically change the incidence of this type of septal deformity in man, at the same time diminishing the possibilities of the onset of cleft lip/palate and REKAS (51).

It is extremely important to again stress that these two types (5 and 6) have nothing to do with trauma against the nose. This is crucial knowledge and should be kept in mind. Type 5 is a very posterior deformity that in many cases remains undiscovered during examination of the nose by simple anterior rhinoscopy. At least decongestion is needed to enable the doctor to see the deepest parts of the nasal cavity. Even then, a very deep septal spine can be overlooked because the mucosa of the turbinates and anterior parts of the septum itself just cover it.

In other words, only endoscopy of the nose is reliable in terms of proving the existence of type 5 .

Type 6 is an extremely anterior deformity, "screaming from the nose", and can be seen immediately after the nasal speculum opens the nostril. Therefore, a typical horizontal groove located between the septum and big, laterally protruding intermaxillary bone wing can by no means be overlooked. Neither can be the basal crest on the opposite side, located in the corresponding position of the groove. There are no data in the literature to prove that there are any signs of fracture, be it of the cartilage or the bone, in these two septal deformities. They belong to the developmental deformities determined by given factors, most probably by some gene sequences that are as yet unknown.

Ethics Committee Approval: Ethics committee approval was received for this study.

Informed Consent: Written informed consent was obtained from patient who participated in this study.
Peer-review: Externally peer-reviewed.

Author contributions: Concept - R.M., N.S.; Design - N.S., G.P., M.Š.; Supervision - R.M., N.S.; Resource - G.P., M.Š.; Materials R.M., N.S., G.P., M.Š.; Data Collection \&/or Processing - R.M., N.S.; Analysis \&/or Interpretation - R.M., N.S.; Literature Search - G.P., M.Š.; Writing - R.M., N.S.; Critical Reviews - R.M., N.S., G.P., M.Š.

Conflict of Interest: No conflict of interest was declared by the authors.

Financial Disclosure: The authors declared that this study has received no financial support.

Editor-in-chief's note: One of the authors of this article, Ranko Mladina is the member of the editorial advisory board of Balkan Medical Journal. However, he did not take place at any stage on the editorial decision of the manuscript.

\section{REFERENCES}

1. Cottle MH, Loring RM, Fischer GG, Gaynon IE. The maxillapremaxilla approach to extensive nasal septum surgery. $A M A$ Arch Otolaryngol 1958;68:301-13. [CrossRef]

2. Mladina R. The role of maxillar morphology in the development of pathological septal deformities. Rhinology 1987;25:199-205.

3. Song SY, Kim IT, Chang KH, Lee KS, Kim HJ, Lim HJ. The Prevalence of Nasal Septal Deformities among Children in Kindergarten and First Grade in Anyang and Kunpo Cities. J Rhinol 1999;6:58-60.

4. Van Loosen J. Post natal development of the human nasal septum and its related structures. Thesis. Erasmus Univeristy Rotterdam. The Netherlands, 2000.

5. Yildirim I, Okur E. The prevalence of nasal septal deviation in children from Kahramanmaras, Turkey. Int J Pediatr Otorhinolaryngol 2003;67:1203-6. [CrossRef]

6. Rao JJ, Vinay Kumar EC, Ram Babu K, Sathavahana Chowdary V, Singh J, Rangamani SV. Classification of nasal septal deviations - Relation to sinonasal pathology. Indian J Otolaryngol Head Neck Surg 2005;57:199-201.

7. Min YG, Jung HW, Kim CS. Prevalence study of nasal septal deformities in Korea: results of a nation-wide survey. Rhinology 2005;33:61-5.

8. Carinci F, Rullo R, Farina A, Morano D, Festa VM, Mazzarella $\mathrm{N}$, et al. Non-syndromic orofacial clefts in Southern Italy: pattern analysis according to gender, history of maternal smoking, folic acid intake and familial diabetes. J Craniomaxillofac Surg 2005;33:91-4. [CrossRef]

9. Oliveira AKP, Júnior EE, Santos LV, Bettega G, Mocellin M. Prevalence of Deviated Nasal Septum in Curitiba, Brazil. Int Arch Otorhinolaryngol 2005;9:288-92.

10. Skitarelic NB, Vukovic K, Skitarelic NP. Comparative evaluation of conventional versus endoscopic septoplasty for lim- 
ited septal deviation and spur. J Laryngol Otol 2009;123:93940. [CrossRef]

11. Zielnik-Jurkiewicz B, Olszewska-Sosińska O.The nasal septum deformities in children and adolescents from Warsaw, Poland. Int J Pediatr Otorhinolaryngol 2006;4:731-6. [CrossRef]

12. Chmielik M, Brożek-Mądry E, Chmielik LP. Influence of the type of septum deviation on some parameters in the upper airways. New Medicine 2006;3:71-3.

13. Neskey D, Eloy JA, Casiano R. Nasal, Septal, and Turbinate Anatomy and Embryology. Otolaryngol Clin N Am 2009:42;193-205. [CrossRef]

14. Teul I, W Zbislawski W, S Baran S, Czerwinski F. Deformation of the nasal septum in children, adolescents, and adults in Western Pomerania Province of Poland. Eur J Med Res 2009;14(Suppl 4):244-7. [CrossRef]

15. Aljibori AS, Hassan AD, Alwan AM. Assessment of nasal septal deformities by anterior rhinoscopy and nasal endoscopy. Tikrit Med J 2010;16:14-20.

16. Huizing EH, de Groot JAM, editors. Functional reconstructive nasal surgery. Stuttgart-New York: Thieme; 2003. [CrossRef]

17. Bianco M, Sanna N, Bucari S, Carmela F, Palmieri V, Zepilli P. Female boxing in Italy: 2002-2007 report. Br J Sports Med 2011;45:563-70. [CrossRef]

18. Sam A, Deshmukh Prsad T, Patil C, Shraddha J, Rashmi P. Nasal Septal Deviation and External Nasal Deformity: A Correlative Study of 100 Cases. Indian J Otolaryngol Head Neck Surg 2012;64:312-8. [CrossRef]

19. Wee JH, Kim DW, Lee JE, Rhee CS, LeeCH, Min YG et al. Classification and prevalence of nasal septal deformity in Koreans according to two classification systems. Acta Otolaryngol 2012;132(Suppl 1):952-7. [CrossRef]

20. Mladina R, Skitarelić NB, Skitarelić NP. The human external nose and its evolutionary role in the prevention of obstructive sleep apnea. Otolaryngol Head Neck Surg 2010;143:712. [CrossRef]

21. Rehman A, Sajad Hamid, Mushtaq Ahmad, Arsalan F. Rashidl. A Prospective Study of Nasal Septal Deformities in Kashmiri Population Attending a Tertiary Care Hospital. Inter J Otolaryngol Head Neck Surgery 2012;1:77-84. [CrossRef]

22. Swenson KE. Nasal septal deviation in a longitudinal growth sample. Master of Science thesis, University of Iowa, Iowa, 2012.

23. Salaheldin AH. Effect of deviated nasal septum and hypertrophy of inferior turbinate on middle ear pressure. Pan Arab J Rhinology 2012;2:59-65.

24. Kanu S, Baldev S, Sanjeev S, BS Verma. Endoscopic septoplasty: prospective study in 50 cases of septal nasal deformity. Clin Rhinol An Int J 2013;6:92-5. [CrossRef]

25. Moore MI. Objective evidence for the efficacy of surgical management of the deviated nasal septum as a treatment for chronic nasal obstruction. Doctoral Thesis. Cardiff School of Biosciences, University of Wales, Cardiff University, Cardiff, 2013.

26. Oswal V, Remacle M, Jovanovic S, Zeitels SM, Krespi JP, Hopper C. Principles and Practice of Lasers in Otorhinolaryngology and Head and Neck. Suregrey. 2nd ed. Amsterdam: Kugler Publication, 2014.
27. Lin JK, Wheatley FC, Handwerker J, Harris NJ, Wong BJF. Analyzing Nasal Septal Deviations to Develop a New Classification System: A Computed Tomography Study Using MATLAB and OsiriX. JAMA Facial Plast Surg 2014;16:183-7. [CrossRef]

28. Zhang Z, Fang S, Zhang Q, Chen L, Liu Y, Li K, et al. Analysis of Complications in Primary Cleft Lips and Palates Surgery. $J$ Craniofac Surg 2014;25:968-71. [CrossRef]

29. Šubarić M, Mladina R. Nasal septum deformities in children and adolescents: A cross sectional study of children from Zagreb, Croatia. Int J Ped Otorhinolaryngol 2002;63:41-8. [CrossRef]

30. Mladina R, Čujić E, Šubarić M, Vuković K. Nasal septal deformities in ear, nose and throat patients: An International Study. Am J Otolaryngol 2008;29:75-82. [CrossRef]

31. Mladina R, Krajina Z. The influence of the caudal process on the formation of septal deformities. Rhinology 1989;27:113-9.

32. Mladina $\mathrm{R}$. The influence of palato-cranial base (basomaxillary) angle on the length of the caudal process of the nasal septum in man. Rhinology 1990;28:185-9.

33. Verwoerd CD, Mladina R, Nolst Trenite GJ, Pigott RW. The nose in children with unilateral cleft lip and palate. Int J Ped Otorhinolaryngol 1995;32:45-52. [CrossRef]

34. Mladina R, Đanić D, Miličić D. Histological changes of the middle turbinate mucosa in various septal deformities. Riv Otolaryngol Aud Fon 1996;3:151-5.

35. Mladina R, Ostojić D, Koželj V, Heinzel B, Bastaić Lj. Pathological septal deformities in cleft palate children. L'Otorinolaryngologia Pediatrica 1997;2-3:75-80.

36. Mladina R, Miličić D, Đanić D. Septal deformities can influence the mucociliary transport impairment of the middle turbinate mucosa. In: Baum G, Priel Z, Roth Y, Liron N, Ostfeld EJ, eds. Cilia, Mucus and Mucociliary Interactions. Marcel Dekker, Inc., New York, 1998:219-28.

37. Jurlina M, Mladina R, Dawidowsky K, Ivanković D, Bumber Ž, Šubarić M. Correlation between the minimal cross-sectional area of the nasal cavity and body surface area: preliminary results in normal patients. Am J Rhinol 2002;16:209-21.

38. Mladina R, Šubarić M. Are some septal deformities inherited? Type 6 revisited. Int J Pediatr Otorhinolaryngol 2003;67:1291-4. [CrossRef]

39. Mladina R, Skitarelić N, Vuković K, Subarić M, Carić T, Orihovac $Z$. Unilateral cleft lip/palate children: The incidence of type 6 septal deformities in their parents. J Craniomaxillofac Surg 2008;36:335-40. [CrossRef]

40. Mladina R, Skitarelić NB, Skitarelić NP. Could we prevent unilateral cleft lip/palate in the future? Med Hypotheses 2009;73:601-3. [CrossRef]

41. Poje G, Zinreich JS, Skitarelíć N, Đuríc Vukovíć K, Passàli GC, Passàli D, et al. Nasal septal deformities in chronic rhinosinusitis patients: clinical and radiological aspects. Acta Otorhinolaryngol Ital 2014;34:117-22.

42. Cingi C, Bayar Muluk N, Acar M, Skitarelić N, Markešić J, Vugrinec $\mathrm{O}$, et al. International study of the incidence of particular types of septal deformities in chronic rhinosinusitis patients: The outcomes from five countries. Am J Rhinol Allergy 2014;28:404-13. [CrossRef] 
43. Guyuron B, Uzzo CD, Scull H. A practical classification of septonasal deviation and an effective guide to septal surgery. Plast Reconstr Surg 1999:104;2202-9. [CrossRef]

44. Buyukertan M, Keklikoglu N, Kokten G. A morphometric consideration of nasal septal deviations by people with paranasal complaints; a computed tomography study. Rhinology 2003;41:21-4.

45. Baumann I, Baumann H. A new classification of septal deviations. Rhinology 2007;45:220-3.

46. Ogura JH, Unno T, Nelson JR. Baseline values in pulmonary mechanics for physiologic surgery of the nose. Preliminary report. Ann Otol Rhinol Laryngol 1968;77:367-97. [CrossRef]

47. Kurkcuoglu S, Titiz A, Olcay İ, Ozcan M, Tuncel U, Unal A. Effect Of Nasal Septal Deviation On Respiratory Function Tests and Arterial Blood Gases. Kulak Burun Bogaz Ihtis Derg 2007; 15:134-8.

48. Miličić D, Mladina R, Đanić D, Prgomet D, Leović D. Influence of nasal fontanel receptors on the regulation of tracheobronchal vagal tone. Croat Med J 1998;39:426-9.

49. Mladina R. REKAS (Recurrent Epistaxis from Kiesselbach's Area Syndrome). Chir Maxillofac Plast 1985;15:91-5.

50. Mladina R, Skitarelić NB, Skitarelić NP. Is recurrent epistaxis from Kiesselbach's area (REKAS) in any relationship to the hemorrhoidal disease? Med Hypotheses 2009;73:955-7. [CrossRef]

51. Ludwig KU, Böhmer AC, Rubini M, Mossey PA, Herms S, Nowak S, et al. Strong association of variants around FOXE1 and orofacial clefting. $J$ Dent Res 2014;93:376-81. [CrossRef] 